Boise State University

ScholarWorks

Civil Engineering Faculty Publications and

Presentations

Department of Civil Engineering

$1-1-2016$

Performance of Aggregate Subgrade Layers in Low Volume Roads Constructed with Unconventional Recycled Aggregates

Hasan Kazmee

University of Illinois at Urbana-Champaign

Erol Tutumluer

University of Illinois at Urbana-Champaign

Debakanta Mishra

Boise State University 
This is an author-produced, peer-reviewed version of this article. The final, definitive version of this document can be found online at Geo-

Chicago 2016, published by the American Society of Civil Engineers. Copyright restrictions may apply. doi: 10.1061/9780784480137.062

\title{
Performance of Aggregate Subgrade Layers in Low Volume Roads Constructed with Unconventional Recycled Aggregates
}

\author{
Hasan Kazmee \\ Graduate Research Assistant \\ University of Illinois at Urbana-Champaign \\ Erol Tutumluer, M. ASCE * \\ Professor, Paul F. Kent Endowed Faculty Scholarf \\ Department of Civil and Environmental Engineering \\ University of Illinois at Urbana-Champaign \\ tutumlue@illinois.edu \\ and \\ Debakanta Mishra \\ Assistant Professor \\ Department of Civil Engineering \\ Boise State University
}

\begin{abstract}
With transportation sector accounting for approximately $27 \%$ of total greenhouse gas emissions, transportation agencies all over United States have made sincere efforts to reduce such carbon footprint by incorporating more recycled materials in design mixes. In Illinois, recycled materials commonly include large sized unconventional aggregates used to stabilize weak subgrade soils that are abundantly found in wet of optimum conditions and prone to frost effects. To facilitate increased use of such "aggregate subgrade” materials, IDOT has recently introduced new gradation bands. However, performance of such recycled aggregate subgrade materials within the bounds of current design framework is largely unknown. To this end, a full scale accelerated pavement test study was undertaken to study six different aggregate subgrade materials involving construction of twelve full scale flexible pavement sections over weak engineered subgrade. Results of accelerated pavement testing on six test sections and performance of three different aggregate subgrade materials are highlighted in this paper including data from quality control tests such as nuclear density gauge, GeoGauge for composite layer modulus, and lightweight and falling weight deflectometers. Current pavement design framework was adequate when designing with two out of three aggregate subgrade materials that constituted different proportions of recycled materials. One noteworthy finding was that asconstructed hot mix asphalt thickness variation was found to be quite large due to reclaimed asphalt pavement subbase sinkage observed during paving operations.
\end{abstract}

\section{Introduction}

Adequate subgrade stability is essential for maintaining a stable working platform for pavement construction and longer service life. Illinois Department of Transportation (IDOT) requires an existing subgrade to have a minimum Immediate Bearing Value (IBV) (also known as unsoaked CBR) of 6\% for placement and construction of pavement layers (Bureau of Bridges and Structures 2005). IDOT Subgrade Stability Manual (SSM) also dictates that rutting under construction traffic must be limited to $12.7 \mathrm{~mm}$ (1/2 in.). Conversely, typical Illinois soils do not meet such ideal conditions due to excessive resilient deformation tendency along with low permeability and high suction potential. Moreover, periodic freeze-thaw actions in the Midwest adversely influence subgrade stability required for long term pavement serviceability. 
This is an author-produced, peer-reviewed version of this article. The final, definitive version of this document can be found online at GeoChicago 2016, published by the American Society of Civil Engineers. Copyright restrictions may apply. doi: 10.1061/9780784480137.062

To this end, IDOT frequently uses a layer of large size granular materials, often referred to as 'aggregate subgrade' for improved subgrade stability. The principal goal for inclusion of such layer is to provide a stable working platform for pavement construction where the existing very weak soil can be rapidly and conveniently improved. In addition, these large size granular materials can be effectively used for mitigating frost action. As a sustainable construction practice, IDOT Bureau of Design and Environment has recently introduced certain gradation bands, i.e. CS01, CS02 and RR01, under the special provision titled as 'Section 303' to allow the use of large size virgin and recycled materials for such improved subgrade applications (Division of Highways 2013).

Due to dimension specific requirements, engineering properties and performance of such large aggregates cannot properly be characterized using standard laboratory tests (Kazmee et al. 2015b). Moreover, current IDOT mechanistic based pavement design procedures do not acknowledge any structural contribution from the aggregate subgrade layer (Heckel 2009). Henceforth, performance trends of these materials are largely unknown. Though past experience in Illinois and other states have often been satisfactory for use of such large size aggregates from virgin sources; there is almost little to no information related to large size recycled materials used for weak subgrade stabilization (Mathis 1991; Uhlmeyer et al. 2003).

In light of the above issues, a full scale pavement test study was undertaken at the University of Illinois to investigate the field performance of low volume asphalt pavements constructed with six different aggregate subgrade materials. Three different recycled materials were selected alongside three different virgin aggregates for construction so that the effect of material composition and source properties could clearly be identified. Totally, twelve full scale test sections were constructed and monitored for surface rut accumulation under accelerated pavement testing. Considering the limited space, this paper has scope to summarize six of these test sections that utilized the selected recycled aggregate subgrade materials.

\section{Design and Construction of Full Scale Test Sections}

Table 1 summarizes the design thicknesses of constructed test sections. The existing subgrade was tilled up to a depth of $30.5 \mathrm{~cm}$ (12 in.) and compacted to a controlled strength of CBR $=1 \%$ and 3\%, respectively. Engineering the subgrade strength was intended to simulate weak soil condition. Details of this procedure can be found elsewhere (Kazmee et al. 2015a). Note that the finished subgrade was sealed with an asphalt binder coating to prevent moisture evaporation. The thickness of aggregate subgrade layer was determined in accordance with the IDOT subgrade stability manual. Four of the test sections were constructed with two different recycled large rocks over CBR $=1 \%$ subgrade; meanwhile, the remaining two sections were built with typical dense graded reclaimed asphalt pavement (RAP) over CBR $=3 \%$ subgrade.

For conventional flexible pavements, IDOT requires a minimum of 20.3-cm (8-in.) thick granular layer surfaced with 7.6-cm (3-in.) thick hot mix asphalt (HMA) layer. Since, the objective of this study to investigate performance trends of low volume roads, the design thicknesses for granular subbase and hot mix asphalt (HMA) were selected to be $15.2 \mathrm{~cm}$ (6 in.) and $10.2 \mathrm{~cm}$ (4 in.), respectively. The thickness of the granular subbase was intentionally scaled down so that the material effect of various aggregate subgrade compositions can be determined. Individual sections were designated with two different alphabetical letters where the first letter identifies the subbase material type and

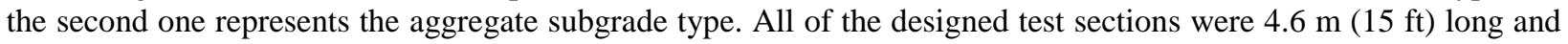
$2.7 \mathrm{~m}(9 \mathrm{ft})$ wide. 
This is an author-produced, peer-reviewed version of this article. The final, definitive version of this document can be found online at GeoChicago 2016, published by the American Society of Civil Engineers. Copyright restrictions may apply. doi: 10.1061/9780784480137.062

Table 1. Design thicknesses of full scale test sections and selected materials

\begin{tabular}{|c|c|c|c|c|c|c|c|}
\hline \multicolumn{2}{|c|}{ Section Designation } & Z-W & $\mathrm{Y}-\mathrm{W}$ & $\mathrm{Z}-\mathrm{X}$ & $\mathrm{Y}-\mathrm{X}$ & $\mathrm{Z}-\mathrm{Y}$ & $Y-Y$ \\
\hline \multirow{3}{*}{$\begin{array}{l}\text { Thickness } \\
\text { (cm) }\end{array}$} & HMA & 10.2 & 10.2 & 10.2 & 10.2 & 10.2 & 10.2 \\
\hline & $\mathrm{SB}^{*}$ & 15.2 & 15.2 & 15.2 & 15.2 & 15.2 & 15.2 \\
\hline & $\mathrm{AS}^{* *}$ & 53.3 & 53.3 & 53.3 & 53.3 & 22.9 & 22.9 \\
\hline \multicolumn{2}{|c|}{ AS Material Type } & \multicolumn{2}{|c|}{$\mathrm{W}$} & \multicolumn{2}{|c|}{$\mathrm{X}$} & \multicolumn{2}{|c|}{$\mathrm{Y}$} \\
\hline \multicolumn{2}{|c|}{ Subgrade CBR (\%) } & \multicolumn{4}{|c|}{1} & \multicolumn{2}{|c|}{3} \\
\hline \multicolumn{8}{|c|}{$\begin{array}{l}\text { *SB = Subbase, } A S^{* *}=\text { Aggregate Subgrade; } \\
{ }^{\uparrow} \text { Odd numbered section: Dolomite (Type Z) subbase, Even numbered section: RAP (Type Y) subbase. }\end{array}$} \\
\hline \multicolumn{8}{|c|}{$\begin{array}{l}{ }^{\uparrow} \text { Type } \mathrm{W}=\text { Crushed concrete aggregates; } \\
\text { Type } \mathrm{X}=\text { Blended recycled aggregates; } \\
\text { Type } \mathrm{Y}=\text { Reclaimed asphalt pavement (RAP) aggregates. }\end{array}$} \\
\hline
\end{tabular}

Each aggregate subgrade type had two different subbase materials namely Type $\mathrm{Z}$ and Type $\mathrm{Y}$ in consecutive sections. Type Z consisted of dense graded dolomite crushed stones; whereas, Type Y comprised of $100 \%$ reclaimed asphalt pavement (RAP) materials screened to $25.4 \mathrm{~mm}$ (1 in.) top size. Type W aggregates originated from concrete demolition waste; whereas, Type X aggregates had $60 \%-40 \%$ blend of large size recycled concrete and RAP. The HMA layer was designed to be constructed in thin lifts $(5.1 \mathrm{~cm}$ or $2 \mathrm{in}$.) of binder and surface courses. The surface course was finer than the binder course having a $9.5 \mathrm{~mm}$ (3/8 in.) nominal maximum aggregate size. A PG 64-22 asphalt binder was used in both of the HMA lifts.

\section{Aggregate Materials Used}

Figure 1(a) shows the particle size distributions of selected aggregate types. Both Type W and Type X aggregate subgrade materials were selected to replicate CS01 gradation band. However, the blended recycled aggregates (Type $\mathrm{X}$ ) were well-graded compared to the Type $\mathrm{W}$ recycled concrete aggregates. Sieve analyses results indicated that the crushed dolomite had approximately 10\% materials passing the No. 200 sieve (0.075 mm), which is significantly higher than that of the remaining aggregate types.

Proper aggregate interlock is essential for improved granular layer performance. Apart from gradation, previous studies reported that aggregate shape properties can also greatly influence granular layer performance (Tutumluer et al. 2000; Tutumluer and Pan 2008). Accordingly, aggregate morphological properties like angularity, surface texture and flat-elongated ratio were also assessed with state of the art field imaging technique and Enhanced University of Illinois Aggregate Image Analyzer (E-UIAIA) (Moaveni et al. 2013). The related results are summarized in Figure 1(b) through $1(\mathrm{~d})$. 
This is an author-produced, peer-reviewed version of this article. The final, definitive version of this document can be found online at GeoChicago 2016, published by the American Society of Civil Engineers. Copyright restrictions may apply. doi: 10.1061/9780784480137.062
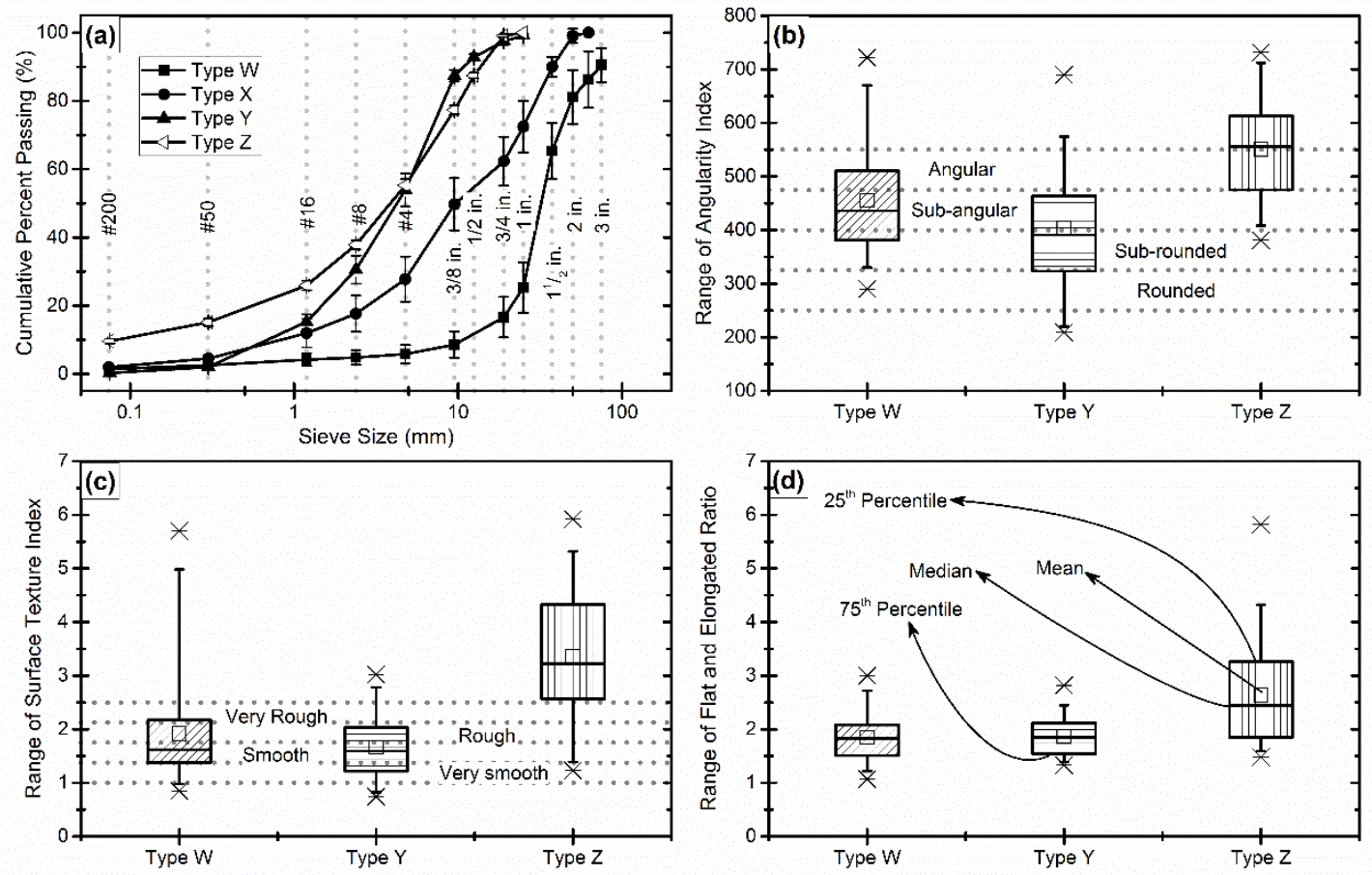

FIG. 1. (a) Particle size distributions, (b) Angularity Index, (c) Surface Texture (ST) index and (d) Flat and Elongated (F\&E) ratio imaging based shape properties of selected materials

The dotted lines in Figure 1(b) and (c) identify the aggregate imaging based shape classifications established earlier (Kwon 2007). From image analyses, Type $Z$ virgin dolomite was significantly angular and rougher compared to the recycled aggregate subgrade materials. Similarly, the dolomite crushed stone exhibited higher flat and elongated ratios. The $75^{\text {th }}$ percentile of angularity index fell into the angular category for Type $\mathrm{Z}$ aggregates whereas those of the recycled aggregate types were found to be in the subrounded category. The $25^{\text {th }}$ and $75^{\text {th }}$ percentiles of surface texture index for the recycled concrete aggregates (RCA) and RAP were found to be varying in between rough and smooth categories. However, Type $\mathrm{W}$ recycled concrete aggregates showed the largest variations in both angularity and surface texture indices among the three aggregate types.

\section{$\underline{\text { In Place Density Assessment }}$}

During placement and compaction, a nuclear density gauge was used to determine the level of compaction achieved in the field. Figure 2 shows the nuclear gauge measured densities and moisture contents along with the target laboratory standard compaction densities identified by dashed lines. Note that the moisture contents obtained in RAP sections were corrected for hydrogen bound materials according to the IDOT procedure (Bureau of Materials and Physical Research 2015). Reported densities in aggregate subgrade was compared with the maximum dry density of Type Y RAP. Section Y-X was reported to have the lowest density owing to large voids present in the aggregate matrix. 
This is an author-produced, peer-reviewed version of this article. The final, definitive version of this document can be found online at GeoChicago 2016, published by the American Society of Civil Engineers. Copyright restrictions may apply. doi: 10.1061/9780784480137.062

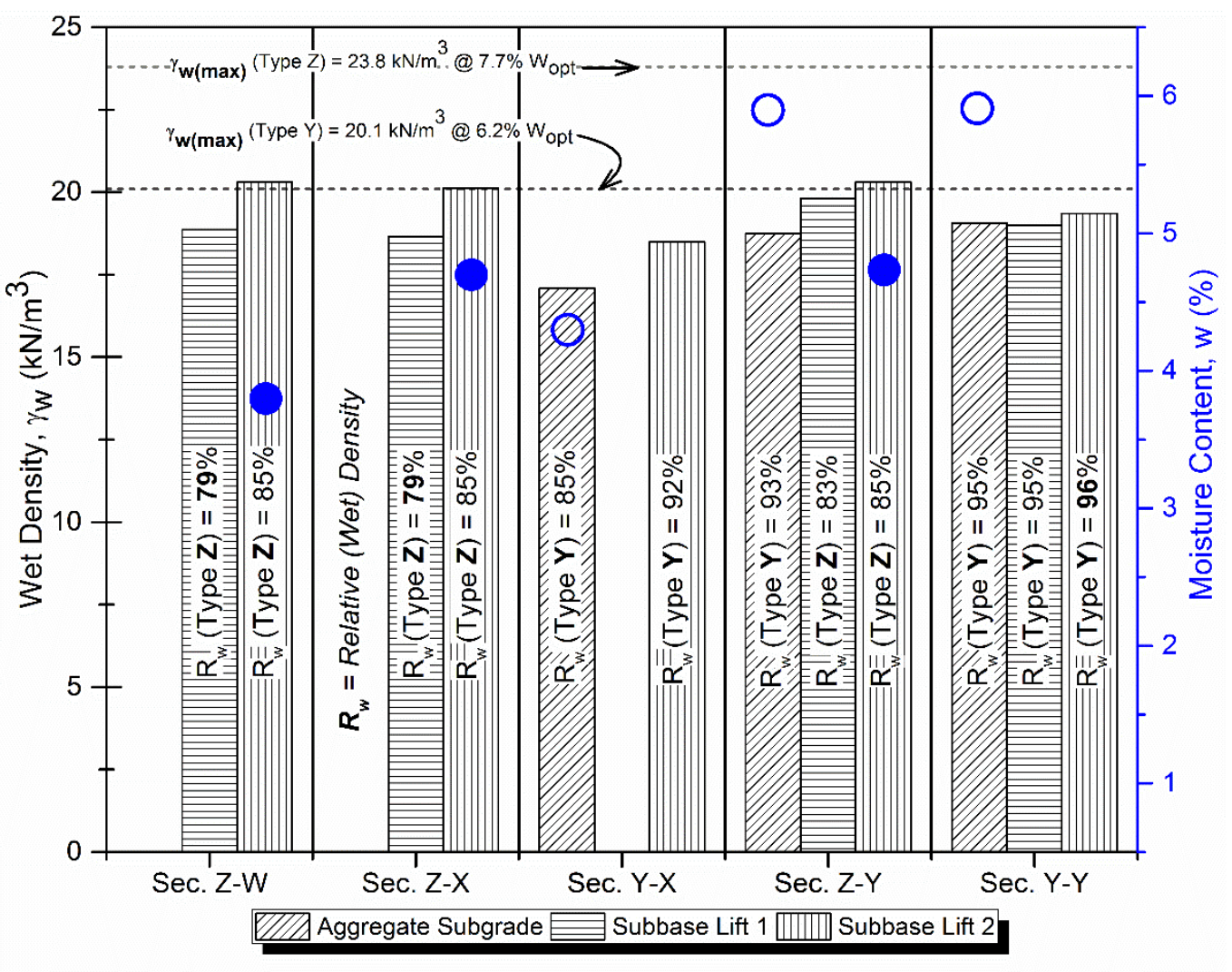

FIG. 2. Achieved densities of granular layers by the nuclear gauge

Subbase aggregates were placed and compacted in two 7.6-cm (3-in.) thick lifts. Since relative compaction achieved in the first lift was not satisfactory with conventional 6-12 roller passes; additionally 6 vibratory roller passes were applied on the second lift of the aggregate subbase layer. Sections Z-Wand Z-X showed significant improvement in achieved densities compared to the other sections. Moreover, the dolomite (Type Z) subbase layers exhibited higher nuclear gauge densities than those for Type Y RAP aggregates. Conversely, relative compaction with respect to corresponding maximum dry density was found to be higher in Type Y RAP subbase sections. Note that, Type Y RAP showed a minimal peak in moisture-density relationship for the standard compactive effort (Kazmee and Tutumluer 2015). As a result, achieving 95\% of maximum dry density was easier in the case of RAP layers. On the other hand, maximum dry density of Type $\mathrm{Z}$ dolomite was almost equal to the density of Portland cement concrete. Moisture contents determined from both nuclear gauge and oven drying procedure revealed that the in place moisture distribution was on the dry side of optimum for dolomite crushed stones. These two factors might have contributed to the low level of relative compaction in Type $Z$ subbase sections. Despite an increase in the compactive effort, the relative density reported for the second lift of Section Y-Y was similar to that of the first lift. Similar trends were also observed in other test sections that are not discussed in this paper for brevity. Thus, the density of Type Y RAP was found to be insensitive to the increase in compaction energy.

\section{$\underline{\text { In Place Modulus Evaluation }}$}

Compacted granular layer stiffness was evaluated using a lightweight deflectometer (LWD) and soil stiffness gauge (GeoGauge). Figure 3 shows the composite surface modulus values recorded for aggregate subgrade and subbase layers. The dotted lines represent corresponding English units at an interval of 34.5 MPa (5 ksi). 
This is an author-produced, peer-reviewed version of this article. The final, definitive version of this document can be found online at GeoChicago 2016, published by the American Society of Civil Engineers. Copyright restrictions may apply. doi: 10.1061/9780784480137.062

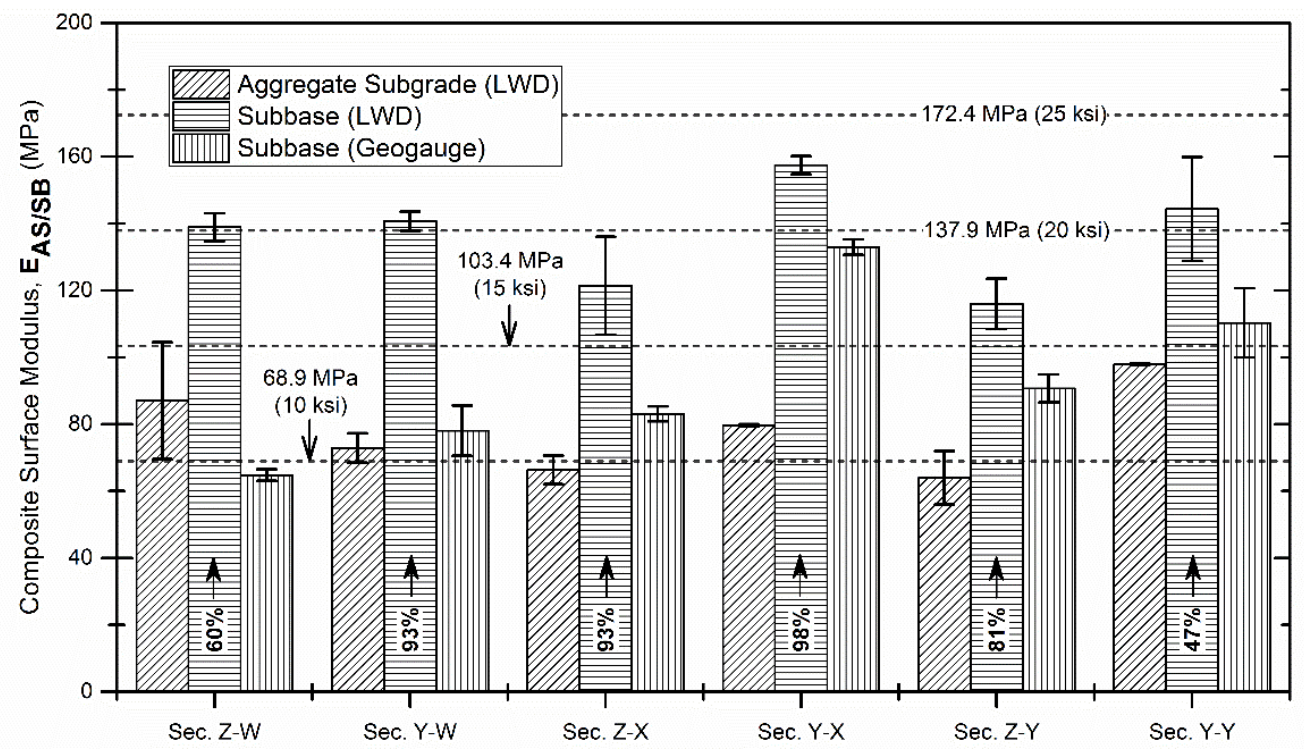

FIG. 3. Composite moduli of constructed aggregate subgrade and subbase layers

Test results indicated that inclusion of dense graded subbase led to an increase in composite modulus values of aggregate subgrade and subbase layers. Note that the large size recycled aggregates with large voids were susceptible to particle movement and reorientation upon due to moving wheel load. That's why, addition of well graded base course size materials helped to confine these large rocks and fill up the voids. As a result, composite stiffness increased significantly in the cases of Type $\mathrm{W}$ and $\mathrm{X}$ aggregate subgrade sections. Owing to dense packing and the highest achieved relative compaction, Section Y-Y exhibited the highest surface modulus among all the sections.

Further, comparing the virgin dolomite and RAP subbase sections on the same aggregate subgrade revealed that the RAP subbase sections exhibited higher modulus values compared to their virgin counterpart. Both LWD and GeoGauge measurements reported the highest stiffness in RAP subbase of Section Y-X. This observation agrees with the laboratory resilient modulus test results previously reported by several researchers (Bennert and Maher 2005; Dong and Huang 2014; Wu 2011).

\section{Rutting Performance}

Upon completion of construction, rut accumulations of the test sections were evaluated through accelerated pavement testing. A super single tire exerting $44.5 \mathrm{kN}$ (10 kip) of load was pulled uni-directionally at a constant speed of $8 \mathrm{~km} / \mathrm{h}$ (5 mph) using the Accelerated Transportation Loading ASsembly (ATLAS). Periodic rutting measurements up to 40,000 passes were conducted at a distance of $1.5 \mathrm{~m}$ (5 ft) from each transverse edge with an automated laser profiler. Over a span of $810 \mathrm{~mm}$, the laser profiler recorded data at an interval of $2 \mathrm{~mm}$. Rutting failure criterion was selected to be $12.7 \mathrm{~mm}(1 / 2 \mathrm{in}$.) in compliance with IDOT guidelines. Figure 4 presents the accumulated rut depth in different test sections with increasing number of passes. 
This is an author-produced, peer-reviewed version of this article. The final, definitive version of this document can be found online at GeoChicago 2016, published by the American Society of Civil Engineers. Copyright restrictions may apply. doi: 10.1061/9780784480137.062

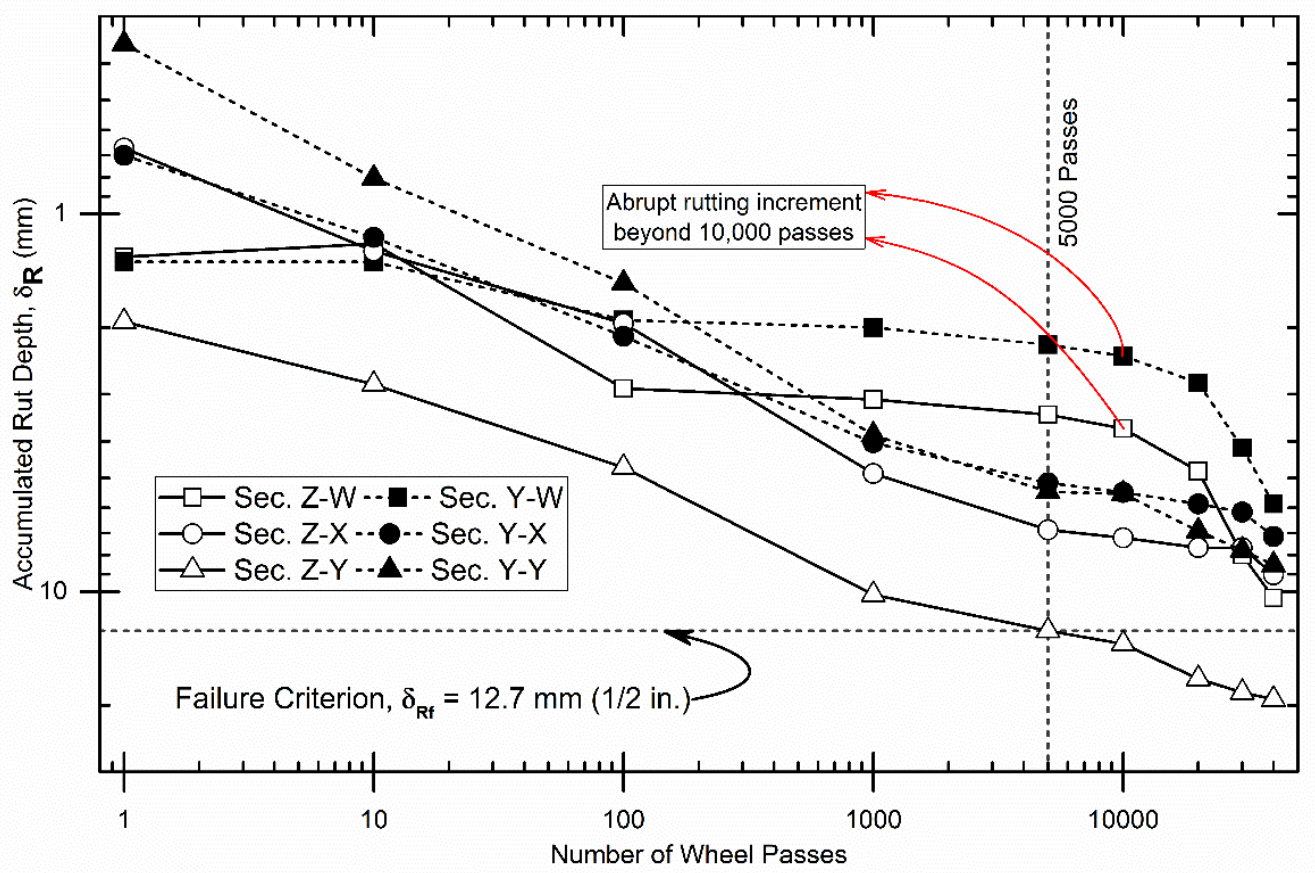

FIG. 4. Surface rut accumulations with traffic in flexible pavement test sections

Rutting trends observed in Figure 4 reveal that sections with Type Y RAP subbase outperformed corresponding Type $\mathrm{Z}$ subbase sections. Moreover, Section Z-Y and Y-Y exhibited the highest discrepancy in rutting accumulation compared to the remaining four sections. In accordance with the previous laboratory studies, the RAP materials were found to produce increased rutting despite having higher resilient moduli (Bennert and Maher 2005; Wu 2011). Superior performance of Type Y RAP subbase sections, however, contradicts with the previously established laboratory permanent deformation trends. Among the six different test sections, only Section Y-X failed at 5,000 passes; whereas the other sections ended up with similar magnitude of rutting at the end of 40,000 passes. Contrary to other sections, Sections Z-W and Y-W exhibited more gradual increases in permanent deformation followed by an abrupt increase in rutting after 10,000 passes. To identify the contributing factors of observed rutting behavior, forensic investigation was conducted by assessment of relative density on cored HMA samples, thickness measurements and trenching. The following section briefly discusses the major findings from pavement forensic investigation.

\section{Forensic Evaluations of Flexible Pavements}

Figure 5(a) shows the extracted hot mix asphalt (HMA) cores at three different locations of transverse measurement lines in Section Z-Y and Y-Y. The thin black line aligned with the HMA samples identifies the target HMA thickness. Overall HMA thickness in Section Y-Y was significantly higher than that of Section Z-Y. The lowest HMA thickness in Section Z-Y was recorded to be $8.6 \mathrm{~cm}$ (3.4 in.). On the other hand, the largest recorded thickness in Section Y-Y was approximately $69 \%$ greater than the lowest recorded thickness of Section Z-Y. Similar to the preceding observation, HMA thickness over RAP subbase were also greater than those of dolomite subbase sections for other aggregate subgrade types. Such large variations in HMA thickness resulted in relatively poor rutting performance of HMA sections with dolomite (Type Z) subbase. Note that bottom surface of HMA layer in each section was examined for probable traces of interface bonding between the HMA layer and underlying RAP granular subbase. However, no such interface bonding was noticed in any of the sections. 
This is an author-produced, peer-reviewed version of this article. The final, definitive version of this document can be found online at GeoChicago 2016, published by the American Society of Civil Engineers. Copyright restrictions may apply. doi: 10.1061/9780784480137.062

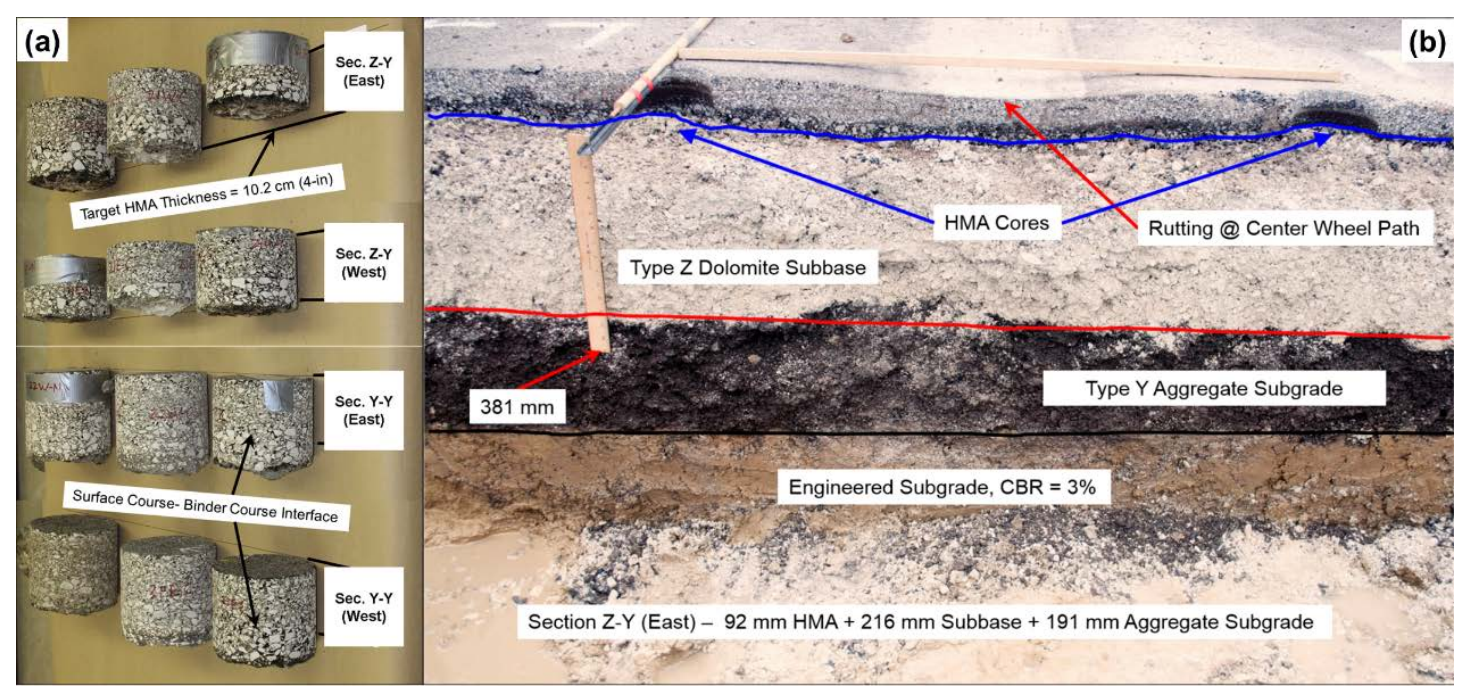

FIG. 5. (a) HMA cores extracted from Sections Y-Y and Z-Y, respectively; (b)

Excavated trench in Section Z-Y

For further investigation, the test sections were trenched so that any discrepancy in granular foundation support or overall pavement thickness could be determined. Figure 5(b) shows the excavated trench in Section Z-Y. According to the figure, primary mode of rutting was observed through the densification of bound HMA layer. Neither the granular layer nor the subgrade exhibited any depression near the wheel path. However, as constructed layer thicknesses were substantially different from the design thicknesses. Type $\mathrm{Z}$ subbase thickness was found to be almost equal to that of Type Y RAP aggregate subgrade. Bulk specific gravity tests were also conducted on the cored samples to determine achieved degree of HMA compaction with respect to the reported theoretical maximum specific gravity. Figure 6 displays the relative compaction of surface and binder courses alongside nuclear gauge readings.

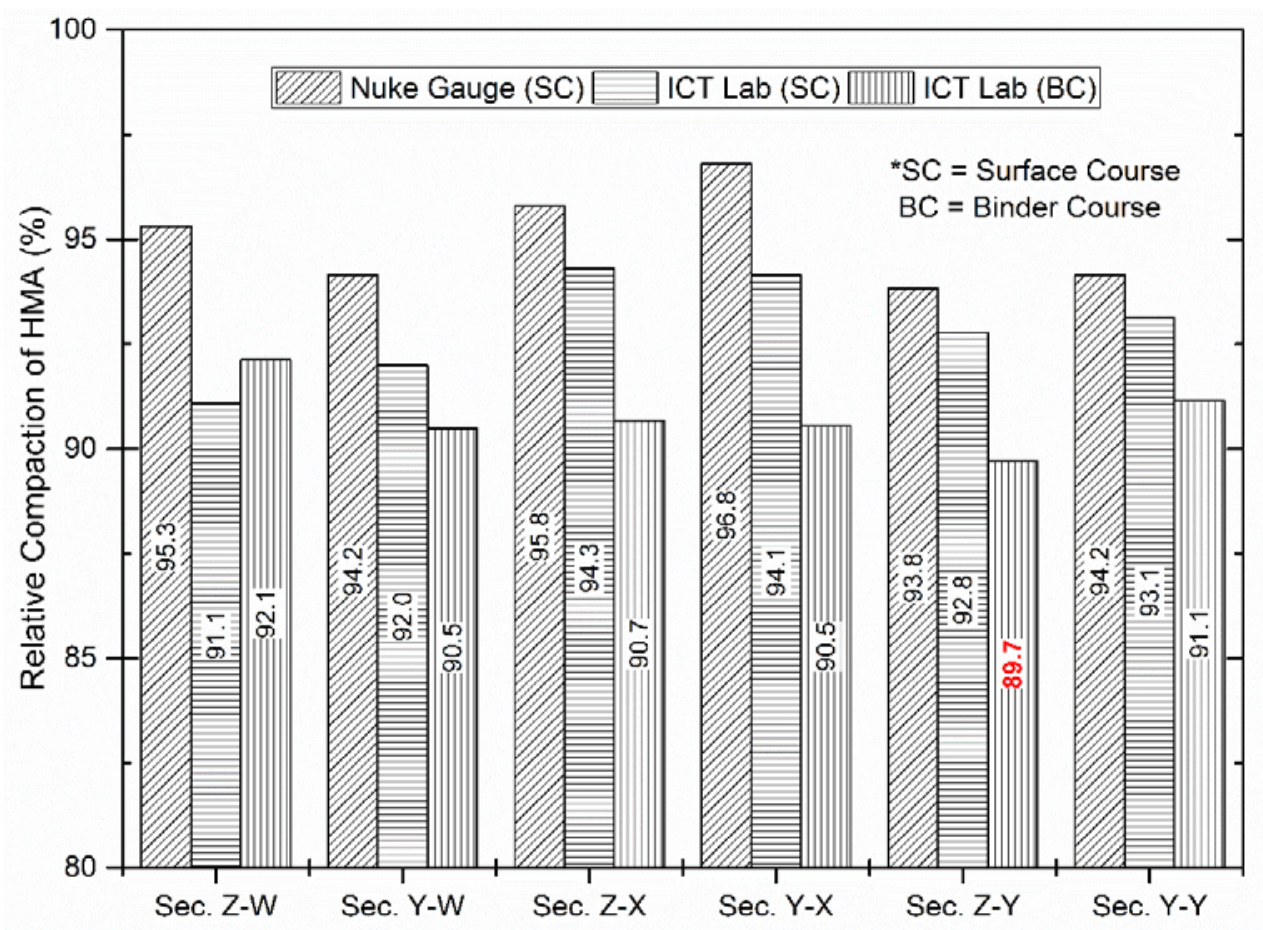

FIG. 6. Relative compaction of HMA layer in constructed test sections 
This is an author-produced, peer-reviewed version of this article. The final, definitive version of this document can be found online at GeoChicago 2016, published by the American Society of Civil Engineers. Copyright restrictions may apply. doi: 10.1061/9780784480137.062

Nuclear gauge densities of HMA surface course were consistently higher than the laboratory measured values. Also, relative densities in the binder course was significantly lower than those of the surface course. The highest magnitude of relative compaction was found to be $97 \%$ in the surface course for Section Y-X; whereas, the lowest degree of compaction was recorded in case of binder course for Section Z-Y. Henceforth, low relative compaction might also be responsible for premature failure of the corresponding test section. However, the influence of density on rutting performance could not be clearly established by comparing the rutting behavior of other sections. Despite having similar HMA thickness and compaction densities in binder layer, Section Y-X exhibited considerably higher permanent deformation than Section Y-W up to 20,000 passes. This indicates that the granular material composition might also be contributing to the differences in rutting behavior.

Considering the above discussion, as constructed layer thicknesses were plotted in terms of elevation in Figure 7 to have a better insight to the rutting trends. The horizontal dotted lines in Figure 7 pinpoint the engineered subgrade interface. According to the figure, pavement surface elevation varied over a wide range and such disparity originated from the aggregate subgrade interface. Note that the total pavement thickness in Type $\mathrm{W}$ aggregate subgrade sections (Sections Z-W and Y-W) was in close proximity to the design thickness. However, as the percentage of RAP materials increased in the subsequent sections, pavement surface elevation along with total thickness also started to fluctuate substantially. In a similar way, the variation in binder layer thickness between the successive dolomite and RAP subbase sections increased significantly as the percentage of RAP in aggregate subgrade blends reached from $0 \%$ to $100 \%$.

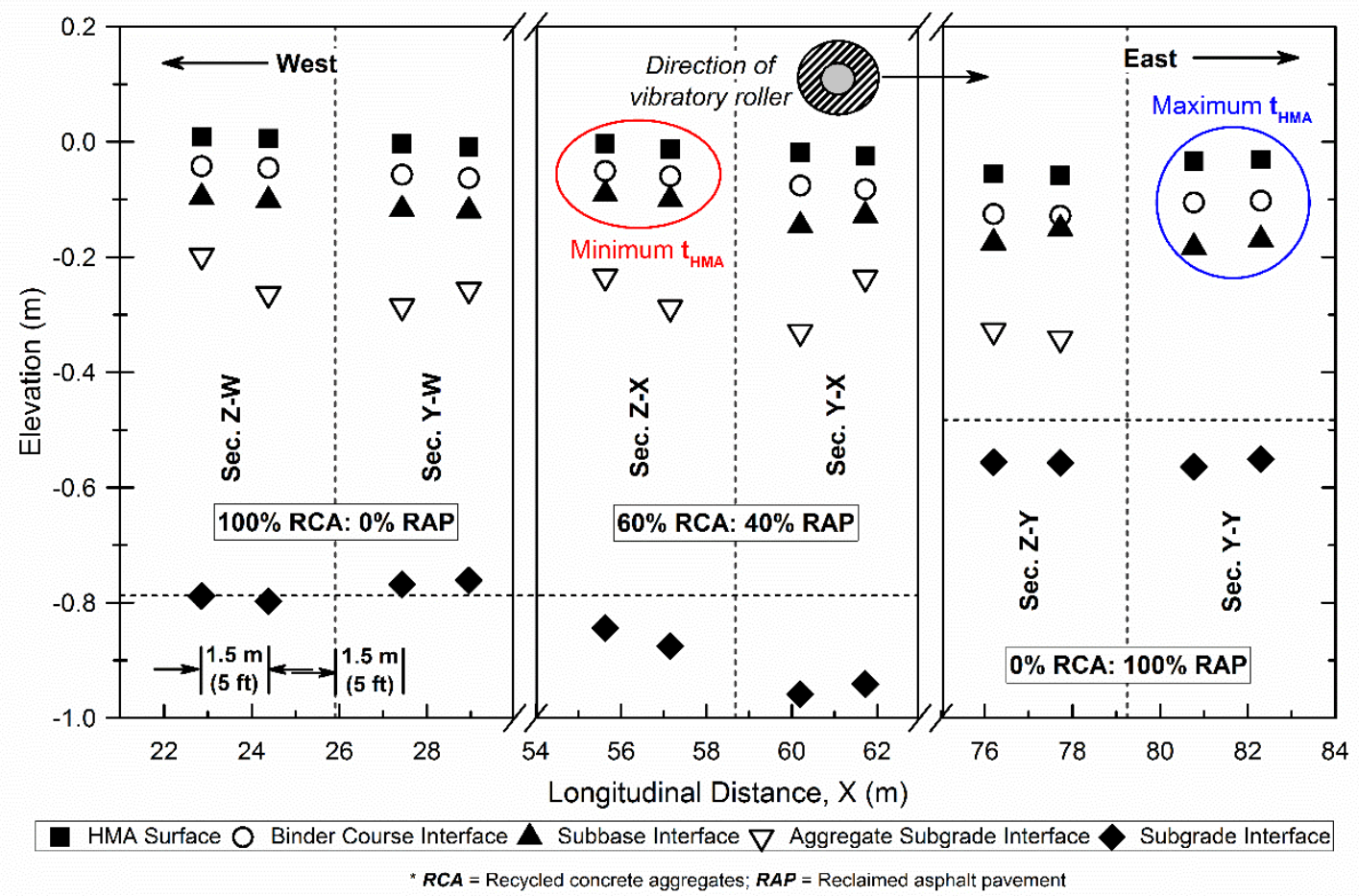

FIG. 7. Longitudinal profiles of HMA test sections at the center of wheel path

Rutting trends and as-constructed layer thicknesses presented in the above discussions narrow things down to four critical factors namely: (i) quality of granular foundation, (ii) HMA thickness, (iii) relative density of HMA layer, and (iv) percentage of RAP in the aggregate blend. The quality of granular foundation became evident from the rutting trends observed in Sections Z-W and Y-W. These two sections accrued less permanent deformation in spite of having less aggregate cover thickness. However, for the same reason, as the traffic exceeded certain critical number of load repetitions, a sharp increase in rutting was observed in those two sections.

Even though the RAP subbase sections accumulated lower permanent deformation, the rutting potential of RAP can still be corroborated. Despite having the lowest HMA thickness, Section Z-X did not fail prematurely; whereas, Section Z-Y which had somewhat higher HMA and unbound granular layer thickness, reached the failure limit at only 5,000 passes. Similarly, Section Y-Y did not exhibit the lowest rutting accumulation in spite of the thickest HMA 
This is an author-produced, peer-reviewed version of this article. The final, definitive version of this document can be found online at GeoChicago 2016, published by the American Society of Civil Engineers. Copyright restrictions may apply. doi: 10.1061/9780784480137.062

layer. Upon closer examination of surface elevation, it can be argued that test sections containing RAP materials accumulated excessive deformation along the direction of compaction during paving operation. Note that surface elevation in Section Y-Y increased because of the proximity to another section containing $100 \%$ virgin aggregate subbase and aggregate subgrade.

\section{Conclusions}

The primary objective of this study was to evaluate the adequacy of three different recycled materials as large size aggregate subgrade materials for improved subgrade applications in conventional flexible pavements. Accordingly, six full scale test sections were constructed and tested for rutting accumulation under accelerated condition. Results from the associated quality control and traffic tests were presented in this paper along with forensic investigation findings to identify pavement rutting mechanisms linked with the use of large size recycled aggregate subgrade foundations. In light of these analyses, the following conclusions can be drawn:

i. The $100 \%$ recycled concrete aggregates (Type W: RCA) and $60 \%-40 \%$ blend of RCA and reclaimed asphalt pavement aggregates (Type X: RAP) surpassed the dense graded Type Y RAP aggregates in terms of rutting performance.

ii. Granular layers containing certain percentage of RAP were prone to sinkage into the soft subgrade during paving operation which cautiously highlighted the increased rutting potential of RAP.

iii. Despite measure lower density and surface modulus characteristics, Type $Z$ virgin dolomite subbase sections did not exhibit any sinkage tendency in comparison to RAP. As a consequence, to maintain same elevation during asphalt paving between two consecutive sections with dissimilar strength and density, the dolomite subbase sections ended up with lower HMA thicknesses.

iv. Use of RAP in improved subgrade applications required higher HMA surface course thickness. Hence, the use of RAP alone as aggregate subgrade and subbase may be cautioned in future sustainable construction practices considering the tendency of RAP layer sinkage on soft subgrade.

\section{Acknowledgements}

The support for this study was provided by the Illinois Department of Transportation (IDOT) as part of the recent ICT R27-124 research project. The authors would like to acknowledge Sheila Beshears from IDOT and others members of the R27-124 Technical Review Panel for their useful advice at different stages of this research. Special thanks go to Illinois Center for Transportation (ICT) research engineers James Meister and Dr. Aaron Coenen, and John Hart and Dr. Maziar Moaveni for characterizing aggregate shape properties. The contents of this paper reflect the views of the authors who are responsible for the facts and the accuracy of the data presented herein. This paper does not constitute a standard, specification, or regulation.

\section{References}

Bennert, T., and Maher, A. (2005). "The Development of a Performance Specification for Granular Base and Subbase Material." Rep. No. FHWA-NJ-2005-003, New Jersey Department of Transportation Bureau of Research and Technology, New Jersey.

Bureau of Bridges and Structures. (2005). Subgrade Stability Manual. Illinois Department of Transportation, Springfield, IL.

Bureau of Materials and Physical Research. (2015). Manual of test procedures for materials. Illinois Department of Transportation, Springfield, IL.

Division of Highways. (2013). "Section 303: Special Provision for Aggregate Subgrade Improvement." Bureau of Design and Environment (BDE) Manual, Illinois Department of Transportation, Springfield, IL.

Dong, Q., and Huang, B. (2014). "Laboratory evaluation on resilient modulus and rate dependencies of RAP used as unbound base material." Journal of Materials in Civil Engineering, 26(2), 379-383.

Heckel, G. (2009). Aggregate Subgrade Thickness Determination. Illinois Department of Transportation, Bureau of Materials and Physical Research. 
This is an author-produced, peer-reviewed version of this article. The final, definitive version of this document can be found online at GeoChicago 2016, published by the American Society of Civil Engineers. Copyright restrictions may apply. doi: 10.1061/9780784480137.062

Kazmee, H., Mishra, D., and Tutumluer, E. (2015a). "Sustainable alternatives in low volume road base course applications evaluated through accelerated pavement testing." Proceedings of The 2015 International Foundations Congress and Equipment Exposition, American Society of Civil Engineers, San Antonio, TX, 409418.

Kazmee, H., and Tutumluer, E. (2015). "Evaluation of aggregate subgrade materials used as pavement subgrade/granular subbase." Rep. No. FHWA-ICT-15-013, Illinois Department of Transportation, Springfield, IL.

Kazmee, H., Tutumluer, E., and Mishra, D. (2015b). "Performance evaluations of pavement working platforms constructed with large-sized unconventional aggregates." Proceedings of Airfield and Highway Pavements Conference, American Society of Civil Engineers, Miami, FL, 849-860.

Kwon, J. (2007). "Development of a mechanistic model for geogrid reinforced flexible pavements". Doctor of Philosophy in Civil Engineering. University of Illinois, Urbana, IL.

Mathis, D. (1991). "Rock Cap: A True Free Draining Base." Proceedings of 42nd Annual Road Builders' Clinic, Coeur D'Alene, ID, 153-156.

Moaveni, M., Wang, S., Hart, J., Tutumluer, E., and Ahuja, N. (2013). "Evaluation of aggregate size and shape by means of segmentation techniques and aggregate image processing algorithms." Transportation Research Record: Journal of the Transportation Research Board, (2335), 50-59.

Tutumluer, E., and Pan, T. (2008). "Aggregate morphology affecting strength and permanent deformation behavior of unbound aggregate materials." Journal of Materials in Civil Engineering, 20(9), 617-627.

Tutumluer, E., Rao, C., and Stefanski, J. A. (2000). "Video image analysis of aggregates." Rep. No. FHWA-IL-UI278, Illinois Department of Transportation, Springfield, IL.

Uhlmeyer, J., Pierce, L., Lovejoy, J., Gribner, M., Mahoney, J., and Olson, G. (2003). "Design and construction of rock cap roadways: Case study in Northeast Washington State." Transportation Research Record: Journal of the Transportation Research Board, (1821), 39-46.

Wu, M. (2011). "Evaluation of high percentage recycled asphalt pavement as base course materials". Master of Science in Civil Engineering. Washington State University, Pullman, WA. 